\title{
Experimental method for creep characterization of polymeric foam materials in media immersion
}

\author{
Gerald Pilz $^{1}$ (D) Peter Guttmann ${ }^{1}$. \\ Florian Oesterreicher $^{1} \cdot$ Gerald Pinter ${ }^{1}$
}

Received: 5 February 2019 / Accepted: 17 July 2020 / Published online: 30 July 2020

(C) The Author(s) 2020

\begin{abstract}
Polymeric flexible foam materials are widely used as damping materials in structural applications primarily to reduce unwanted system vibrations and related noise generation. Due to the viscoelastic nature of polymers and high compressibility of soft polymeric foams, their damping quality is strongly dependent on the overall loading situation, which occasionally means complex mechanical loading scenarios combined with specific ambient service conditions. In the case of superimposed constant compressive loading the deformation of the damping components is basically dependent on the fundamental creep tendency of certain material type and is also strongly influenced by service temperature and the surrounding contact media. Thus the chosen test methodology for proper creep characterization has to reflect these major influencing parameters.

In this regard, a specific creep testing device was built up for the performance of small load compression creep experiments on soft foam specimens immersed in liquid media, which was mineral oil in the present study. Moreover, the thermo-mechanical behavior of the foam materials was investigated by dynamic-mechanical analysis (DMA). The resulting temperature-dependent modulus and damping characteristics showed a good correlation with the corresponding creep behavior, enabling a rough estimation of the creep tendency within corresponding temperature ranges.
\end{abstract}

Keywords Polymer foams $\cdot$ Compression properties $\cdot$ Creep testing $\cdot$ Media influence $\cdot$ Oil immersion

\section{Introduction}

Noise reduction and energy saving issues are among the major challenges in the construction industry and machinery sector. Due to the viscoelastic properties of polymeric materials on the one hand and their thermal insulation quality on the other, polymers are the preferred

\footnotetext{
$凶$ G. Pilz

gerald.pilz@unileoben.ac.at

1 Chair of Materials Science and Testing of Polymers, Montanuniversitaet Leoben, Leoben, Austria
} 
materials in this regard (Corsaro and Sperling 1990; Defonseka 2013; Sonnenschein 2014). Nevertheless, for successful application of polymeric materials the overall loading situation in service such as the time- and temperature-dependent deformation behavior and possible media influence are of major importance. In the special case of polymeric foam materials the fundamental viscoelastic properties of the underlying polymer (Ferry 1980; Hellerich et al. 2010; Ehrenstein and Theriault 2001) and load-dependent deformation of the specific cell structure is decisive for the overall deformation behavior (Gibson and Ashby 1999; Ashby 2006; Eaves 2004; Szycher 2013; Mills 2007).

According to the respective field of applications, commercial polyurethane foam materials are available in various formulations of the polymer type, closed or open cell structured in adjustable grades of density. All these parameters determine the deformation behavior of the elastomeric foam, which in general can be categorized as elastic and reversible. In the case of low-density foam types with large pore spaces, typically three regions of different stressstrain behavior can be distinguished in uniaxial compression (Gibson and Ashby 1999; Briody et al. 2012). Initially, the bending and compression of cell walls and edges lead to approximately linear stress-strain correlation up to strains of about 5\% (region I).

The following stress plateau (region II) with moderate and constant stress increase up to a compression strain level of about $60 \%$ is dominated by viscoelastic cell wall buckling and initial cell collapse. This region represents the area of the highest energy absorption without significant structural damage and is therefore the recommended area for damping applications. Finally, the stress-strain curve ends up in the densification regime of the foam (region III), with significant increase of compression stress due to intense cell wall contact, density increase, and thus structural damage.

Concerning the overall loading situation in common structural applications, especially static long-term loading is predominant for load carrying damping elements. Consequently, the resulting time-dependent deformation behavior determines the damping quality of the component for superimposed dynamic-mechanical loading.

Further on, surrounding environmental impact such as elevated temperatures and media contact strongly influences the mechanical behavior especially for foam materials with extensive media uptake. Liquid medium fills up the cellular volume to a certain extent, which influences the structural deformation behavior of the foam component (Biot 1962; Cheng 2016). Moreover, the media contents of the polymer itself may result in a softening effect along with a shift of glass transition toward lower temperature.

Considering the complex loading profile of mechanical short- and long-term loads in combination with environmental influencing factors, a corresponding loading scenario is also necessary for proper materials testing and the reliable estimation of service performance. In this regard, the prime goal of the present study was the establishment of a suitable procedure for creep tests on polyurethane (PUR) foam materials immersed in mineral oil, which is also a typical loading scenario for supporting components in the machinery. This involves the development and implementation of a proper small load compression testing device, which enables the performance of compressive creep tests in media immersion at elevated temperatures. The resulting creep deformation was monitored as a function of time and further evaluated in the form of corresponding creep compliance curves $D_{\mathrm{c}}(t)$ as the usual presentation of the creep properties. Further on, the creep behavior of various PUR foam materials was compared to their thermo-mechanical properties such as the elastic storage modulus $E^{\prime}$ determined by additional dynamic mechanical analysis (DMA). Thereby, a further correlation between the time- and temperature-dependent materials performance was established. 
a)

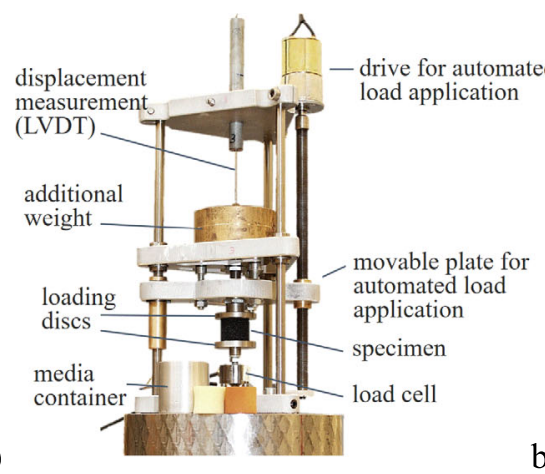

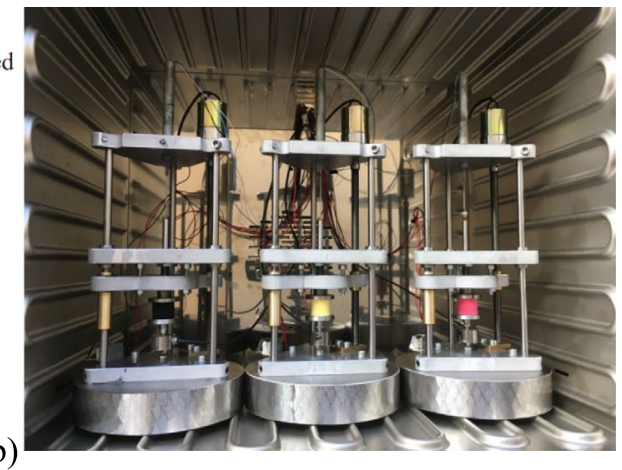

Fig. 1 Compression test device for creep tests on soft materials at elevated temperatures in media immersion: single components (a, left); complete equipment in temperature camber (b, right)

\section{Experimental}

For the characterization of soft polymeric foam materials under static long-term compression load, at first a proper testing device for application-related creep tests under direct media contact at elevated temperatures had to be developed. Thus the following features were in special focus: variable compression loading in the small load range, test performance at various elevated temperatures, and continuous deformation measurement of the foam specimens in media immersion. In this regard, a creep testing device was built up consisting of three compression loading units, which were separately controllable by an automated test start feature and implemented sensors for continuous load and displacement measurement (see Fig. 1). Each test rig was equipped with a small media container providing the performance of long-term creep measurements in a constant saturated material state (in the present case, foam specimens immersed in mineral oil).

After the test specimen was placed inbetween the loading plates in the media container at the bottom plate, static load was applied by drive controlled downward moving of the upper loading plate with defined additional weight. Once full load was reached, the applied deadweight provided constant compression force over the entire measuring time. The creepdeformation was measured continuously by an LVDT placed on top of the moveable loading plate. All three test rigs were operated simultaneously in a standard temperature camber to perform the creep tests at various elevated temperatures.

Subsequently, the compression test device was implemented by a series of creep tests on various commercially available polyurethane foam grades provided by Getzner Werkstoffe $\mathrm{GmbH}(\mathrm{A})$. The chosen materials are commonly used for various damping applications at different load levels and thus show distinct variations in cellular structure and stiffness. An overview of the investigated foam types is given in Table 1 along with some of their characteristic properties.

By the use of cylindrical foam specimens (diameter: $20 \mathrm{~mm}$, height: $20 \mathrm{~mm}$ ) the single creep experiments were performed for loading times of 24 hours at constant compressive stress levels. With the prime goal to reach a creep deformation regime within compression region II, appropriate loading weights were chosen for various materials states also accounting for the buoyancy of the foam specimens in oil immersion. The resulting compression stresses $\sigma_{0}$ directly measured underneath the foam specimens were ranging from 0.012 to $0.103 \mathrm{MPa}$ for various material states. 
Table 1 Investigated polyurethane (PUR) soft foam materials provided by Getzner Werkstoffe GmbH

\begin{tabular}{llll}
\hline Commercial grade & Sylomer SR11 & Sylomer HD30 & Sylodyn NB \\
\hline code $^{\mathrm{a}}$ & FPF-op1 & FPF-op2 & FPF-cl1 \\
\hline Color & Yellow & Blue & Pink \\
Cellular structure & open cells & open cells & closed cells \\
Density $\rho, \mathrm{kg} / \mathrm{m}^{3}$ & 155 & 175 & 335 \\
Operating temp. range, ${ }^{\circ} \mathrm{C}$ & -30 to 70 & -30 to 70 & -30 to 70 \\
Glass transition temp., ${ }^{\circ} \mathrm{C}$ & -45 & 15 & -45 \\
Creep load dry state, $\mathrm{MPa}$ & 0.012 & 0.026 & 0.099 \\
Creep load in oil, MPa & 0.021 & 0.031 & 0.103 \\
\hline
\end{tabular}

a Abbreviations for the materials specifically used within the present study

Each stress level was given by the specific loading force $\mathrm{F}$ divided by the cross-section of the specimens $A_{0}$ in the unloaded state. The continuously measured compressive deformation divided by the initial specimens height results in the time-dependent creep strain $\varepsilon_{\mathrm{c}}(t)$, which was the basis for the further calculation of the compressive creep compliance as follows:

$$
D_{c}(t)=\frac{\varepsilon_{c}(t)}{\sigma_{0}}
$$

To characterize the influence of elevated temperature and oil content on the creep properties of the foams, the corresponding creep tests were performed in air and in oil immersion at 23 and $60^{\circ} \mathrm{C}$. Because of the typical application of PUR damping components in the machinery, for example, in cooling compressors, the refrigeration oil RenisoWF5A46 based on mineral oil was used for specimens conditioning. The oil-saturated materials state was provided by the storage of the foam specimens immersed in the test medium for 14 days at $60^{\circ} \mathrm{C}$, and the time-dependent oil uptake was monitored. As expected, the amount of oil uptake is closely related to the cell structure, which means high relative mass increase of 400 and 500 wt-\% for the open cell foam types FPF-op1 and FPF-op2 and a significantly reduced corresponding value of about $40 \mathrm{wt}-\%$ for the closed cell foam type FPF-cl1; see Fig. 2. This is due to the smaller scaled cell volume of FPF-cl1 with cell diameters of about $130 \mu \mathrm{m}$ compared to the open cell structured foams with cell diameters up to about $350 \mu \mathrm{m}$ along with reduced deformability and permeability of the predominantly closed cell wall structures. Further detailed investigations concerning the oil contents under creep load and the corresponding poroelasticity of the foam materials were not carried out within the scope of this study. However, it should be noted that intercellular fluid content and thus the interaction between fluid flow and foam structure under load significantly influence the overall deformation behavior of the porous medium (Biot 1962; Cheng 2016). Particularly, the permeability of the present foam materials primarily determined by open vs. closed cell structures and the softening effect of the mineral oil on the polymeric material itself may be mentioned in this concern.

Prior to creep testing, cyclic short-term compression tests were performed for a basic characterization of the deformation behavior of the soft foam materials in dry state, also as a guidance for the definition of appropriate stress levels for the subsequent creep tests. The cylindrical foam specimens (diameter: $20 \mathrm{~mm}$, height: $20 \mathrm{~mm}$ ) were placed inbetween the parallel compression plates of a Zwick Z010 universal testing device (Zwick, Ulm, D) 

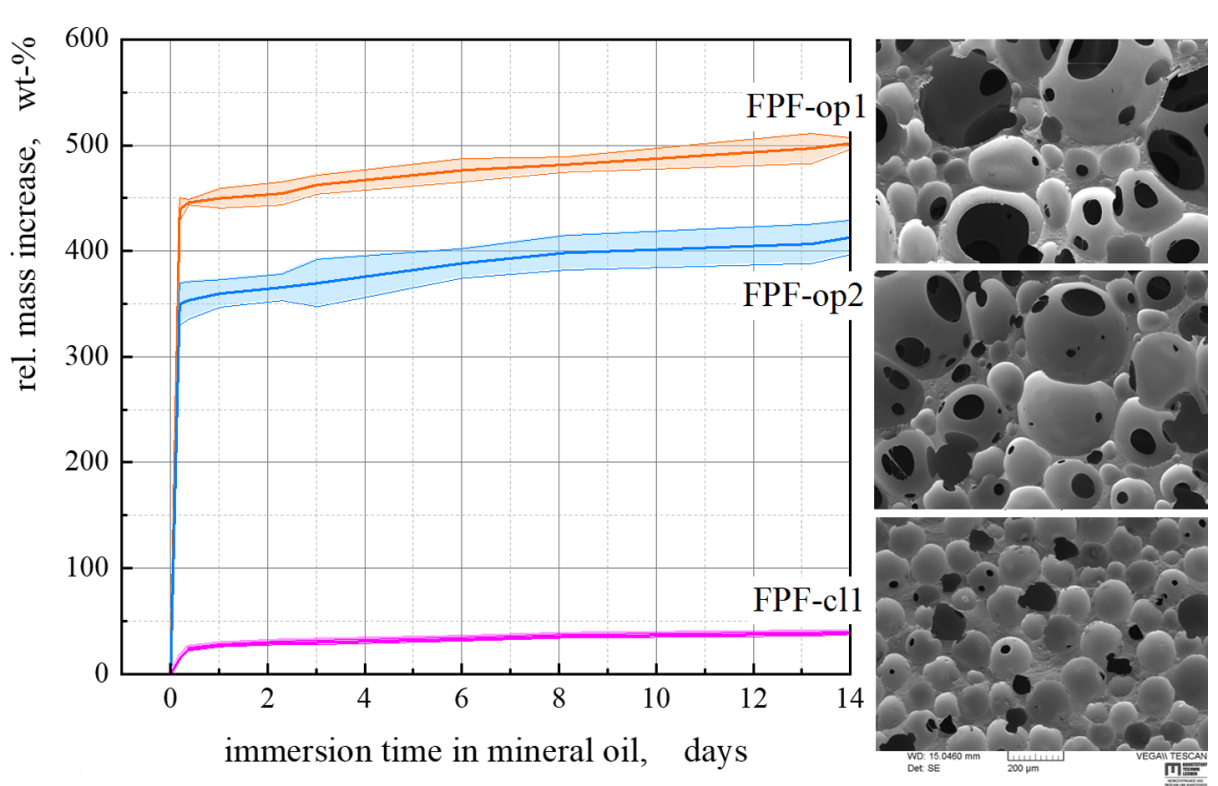

Fig. 2 Time-dependent oil absorption of open and closed cell PUR foam types in oil immersion at $60{ }^{\circ} \mathrm{C}$ and SEM images of the corresponding cell structures

with a load cell capacity of $500 \mathrm{~N}$. Monotonic loading and unloading cycles (10 cycles in each experiment) were applied with a test speed of $500 \mathrm{~mm} / \mathrm{min}$ up to a compression strain of $50 \%$. In each test the last loading cycle was extended to ultimate foam densification (compression strain $>60 \%$ ).

Finally, additional dynamic-mechanical analysis was performed on a DMA device type MCR 702 MultiDrive (Anton Paar, Graz, A) in compression mode to characterize the temperature dependency of the mechanical properties such as elastic storage modulus $E^{\prime}(T)$ and mechanical loss factor tan $\delta$. In the DMA tests, cylindrical specimens (diameter: $5 \mathrm{~mm}$, height: $5 \mathrm{~mm}$ ) were loaded by precompression of $20 \%$ (respective specimens height under preload: $4 \mathrm{~mm}$ ) to reach the relevant compression plateau region II. The precompressed state was superimposed by a dynamic displacement amplitude of $250 \mu \mathrm{m}$ at a frequency $f$ of $1 \mathrm{~Hz}$. Temperature was increased from 30 up to $100^{\circ} \mathrm{C}$ by a constant heating rate of $2 \mathrm{~K} / \mathrm{min}$. Based on the applied dynamic compression strain amplitude $\varepsilon_{A}$, the resulting stress amplitude $\sigma_{A}$ was measured, and the complex modulus $E^{*}$ was calculated as follows:

$$
\left|E^{*}\right|=\frac{\sigma_{A}}{\varepsilon_{A}} .
$$

Along with the also measured time shift $\delta / \omega$ between stress and strain, the storage modulus $E^{\prime}(\omega)$ was determined for the test frequency $f(\omega=2 \pi f)$ of $1 \mathrm{~Hz}$ as follows:

$$
E^{\prime}(\omega)=\left|E^{*}\right| \cdot \cos \delta
$$

Further on, the storage modulus, which is roughly equal to the elastic modulus for a single rapid stress at low load and reversible deformation (Ehrenstein et al. 2004), was compared to the corresponding creep properties of various foam materials. In this concern, the temperature dependency of the storage modulus may provide a useful guidance at least for a qualitative estimation of the creep behavior. 


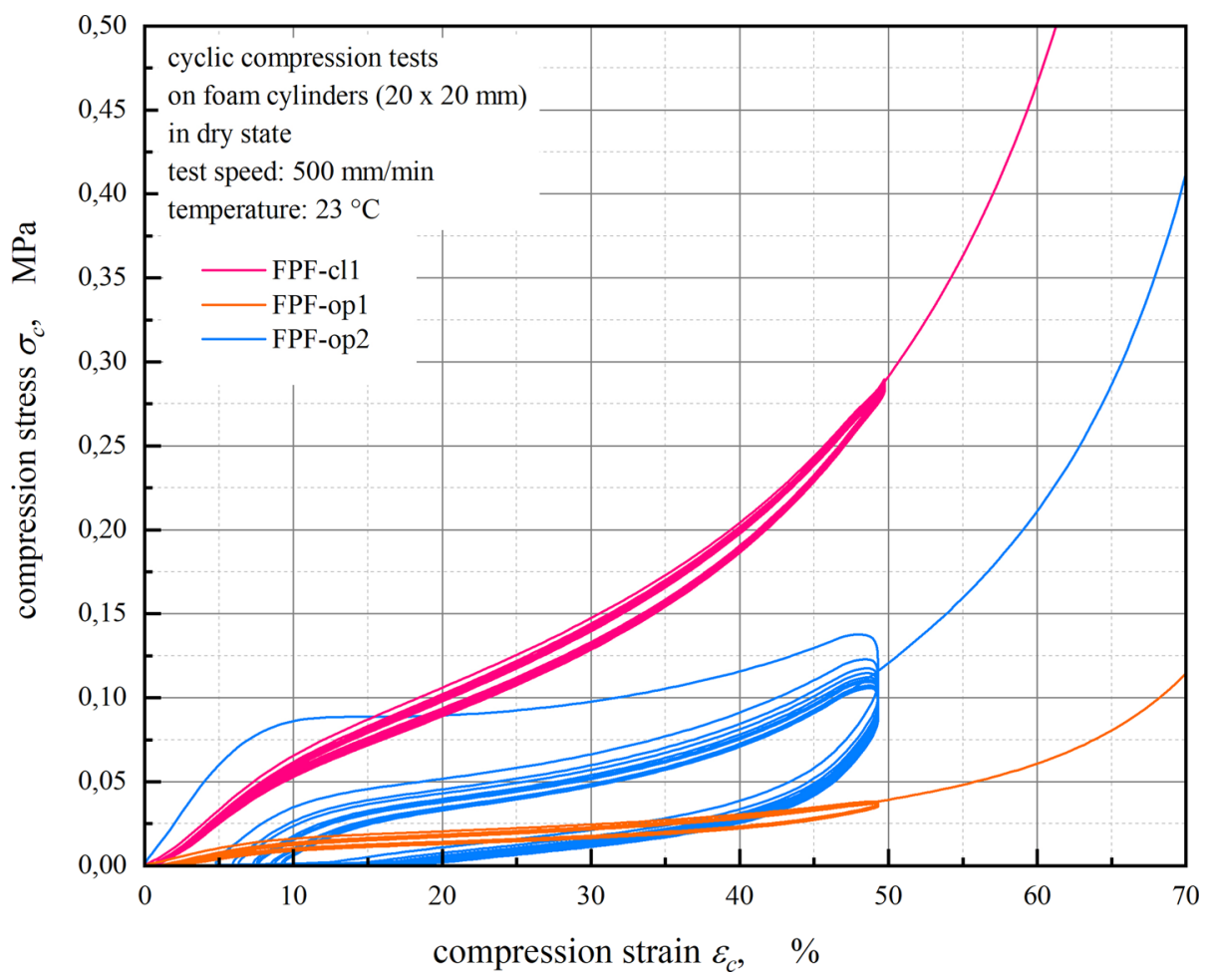

Fig. 3 Compression stress vs. strain curves for various soft foam types in dry state at $23{ }^{\circ} \mathrm{C}$ by cyclic loading and unloading (10 cycles) and final compression up to foam densification

\section{Results}

A comprehensive overview of the compression behavior of various soft foam types in dry materials state at $23{ }^{\circ} \mathrm{C}$ was provided by the results of the cyclic compression tests (see Fig. 3). The characteristic three different regions of stress-strain behavior can be distinguished more or less pronounced depending on the specific foam type. Whereas the closed cell structured foam FPF-cl1 shows distinct stress increase over the whole range of compression with only small flattening in region II, the open cell foam types FPF-op1 and FPF-op2 reveal the typical plateau regime with only small stress increase over a wide compression strain range. Moreover, the included curve area within the loading and unloading cycles corresponds to the damping capability of the material, which is the largest for FPF-op2. Besides structural effects of this open cell foam, particularly its glass transition temperature of $15^{\circ} \mathrm{C}$, which is close to the test temperature, has a strong viscoelastic effect on the materials behavior revealing distinct mechanical losses.

Moreover, an analogous series of compression tests for the oil saturated materials state at $60{ }^{\circ} \mathrm{C}$ is shown in Fig. 4 compared to the corresponding results for the dry reference state at $23{ }^{\circ} \mathrm{C}$. Whereas for the materials FPF-cl1 and FPF-op1, the oil immersed state at $60^{\circ} \mathrm{C}$ leads to a comparable small decline of the compression stress level at similar damping behavior, a much stronger effect of oil immersion was observed for foam type FPF-op2. The significant drop in the compressive stress level with simultaneously reduced damping 


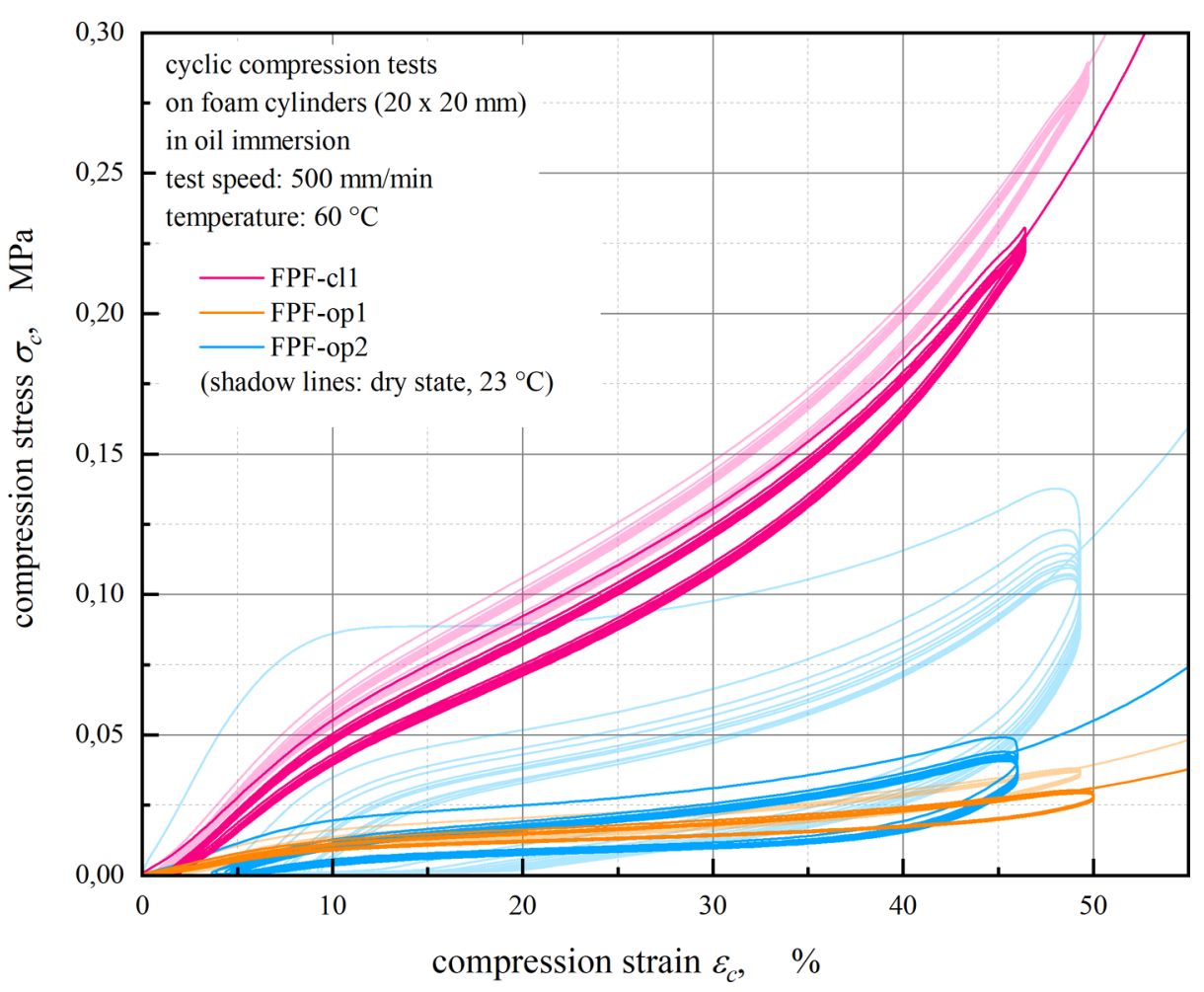

Fig. 4 Compression stress vs. strain curves for various soft foam types in oil immersion at $60{ }^{\circ} \mathrm{C}$ for 10 loading and unloading cycles and the corresponding reference curves for the dry state at $23{ }^{\circ} \mathrm{C}$ (shadow lines)

capacity is probably due to the decreasing influence of the glass transition, which is $15^{\circ} \mathrm{C}$ for this foam type.

To reach compression strain in the creep experiments within a range of about 10 to $60 \%$ (compression region II), which is recommended for optimal damping performance, the corresponding creep stress levels had to be defined. Considering the specific foam types and test conditions (temperatures $23^{\circ} \mathrm{C}$ and $60^{\circ} \mathrm{C}$, materials states dry and oil-saturated), appropriate loading weights were chosen for various creep tests with resulting stress levels ranging from 0.012 to $0.103 \mathrm{MPa}$. Particularly for the oil immersed state, higher loading weights were chosen to account for the buoyancy of the test specimens still ensuring a resulting loading stress within compression region II. Figure 5 gives a comprehensive overview of the creep behavior showing the creep strain curves $\varepsilon_{\mathrm{c}}(t)$ for various foam types and test conditions. The reached compression strain range roughly coincides with the intended and service relevant compression region II recommended for optimal damping.

Obviously, direct comparison of materials regarding initial deformation after loading and resulting creep rates is limited due to different loading stresses. However, the following general remarks are to be stated concerning the dependency of creep behavior of the foams on the various test conditions such as elevated temperature and media immersion.

Material type FPF-op1 was tested at creep stresses of 0.012 and $0.021 \mathrm{MPa}$ to reach an overall creep deformation regime (plateau region II) for various test conditions at $23{ }^{\circ} \mathrm{C}$ and $60^{\circ} \mathrm{C}$ in air and in oil immersion at $60^{\circ} \mathrm{C}$. Thus the initial creep compliance levels $D_{\mathrm{c}}(t)$ were significantly differing, showing a small initial increase of the short-term compliance 


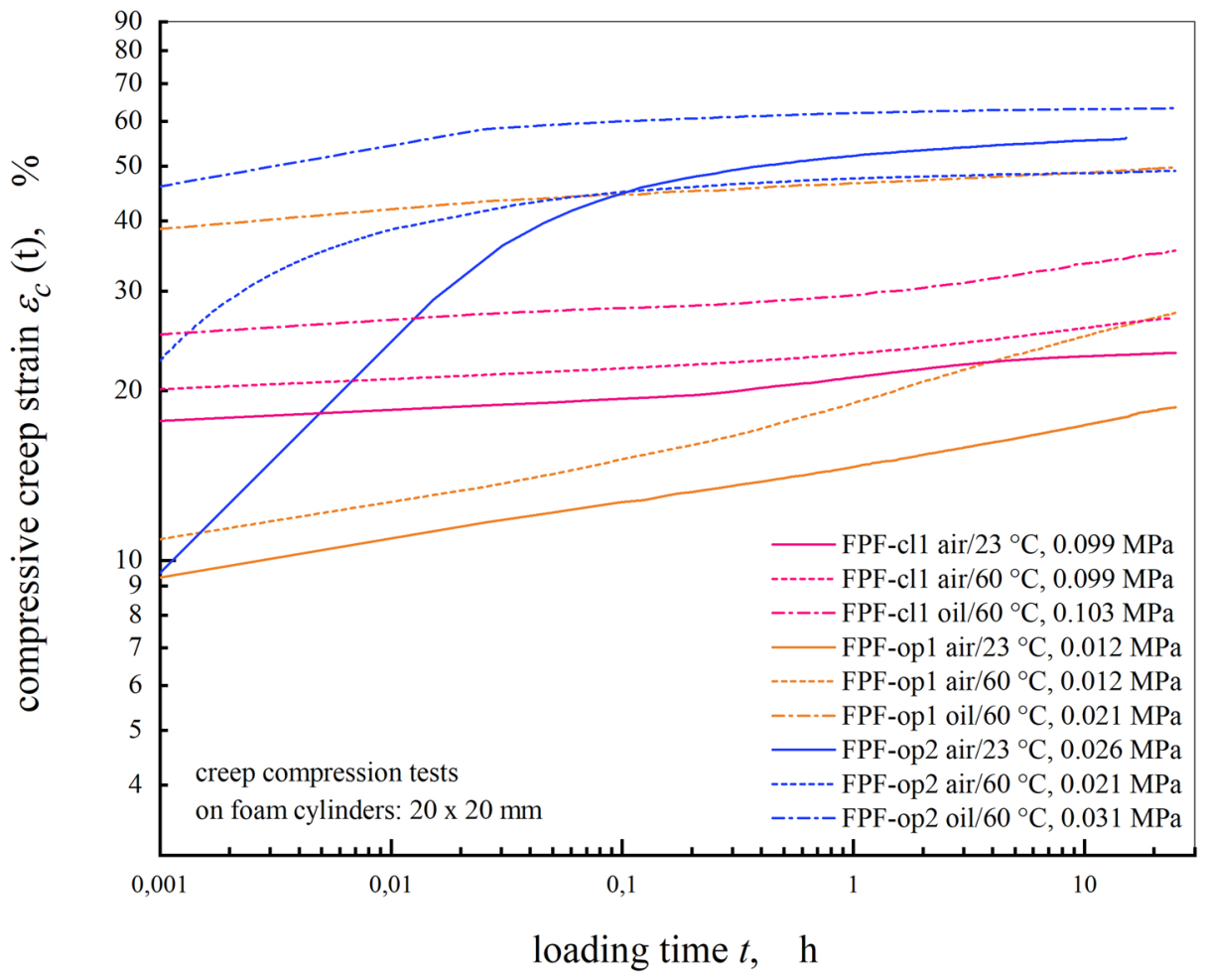

Fig. 5 Creep strain curves $\varepsilon_{\mathrm{c}}(t)$ for various soft foam types and test conditions: stress levels 0.012 to 0.103 $\mathrm{MPa}$, temperatures $23^{\circ} \mathrm{C}$ and $60^{\circ} \mathrm{C}$, materials states dry and oil-saturated

from about 8.5 to $10 \mathrm{MPa}^{-1}$ due to the elevated temperature of $60{ }^{\circ} \mathrm{C}$. The creep test at $60{ }^{\circ} \mathrm{C}$ also reveals the largest creep rate for the dry material state ending up at a creep compliance level of about $23 \mathrm{MPa}^{-1}$ (see Fig. 6) after a loading time of 24 hours. On the other hand, a large increase of the initial compliance to about $19 \mathrm{MPa}^{-1}$ was noticed for the oil immersed state. The corresponding compression strain of $40 \%$ is close to the regime of significant foam densification (cf. Figs. 3 and 4), which for the oil immersed state at $60^{\circ} \mathrm{C}$ is reached in the initial loading phase along with comparatively low creep tendency. Besides the general acceleration of the creep rate at increased temperatures (Ferry 1980), in the case of PUR materials, elevated temperatures are known to cause hydrogen bond disruption, which leads to an additional increase of the creep rates in the temperature range investigated (Kaushiva 1999).

Analogous creep tests were performed for the second open cell PUR foam type FPF-op2 at increased load levels of 0.026 and $0.031 \mathrm{MPa}$ to reach the relevant foam compression range within region II. The resulting creep compliance curves $D_{\mathrm{c}}(t)$ for various test conditions ( 23 and $60^{\circ} \mathrm{C}$ in air, $60^{\circ} \mathrm{C}$ in oil immersion) are shown in Fig. 7. Significant timedependent increase of the creep compliance in the initial phase of the creep tests is ending up in a compression regime with distinctly reduced creep tendency for longer loading times. Whereas this is evident especially for a test temperature of $23^{\circ} \mathrm{C}$, the elevated temperature of $60^{\circ} \mathrm{C}$, particularly for the oil immersed state, leads to a large immediate increase of the creep compliance reaching a densified condition with reduced creep rate. 


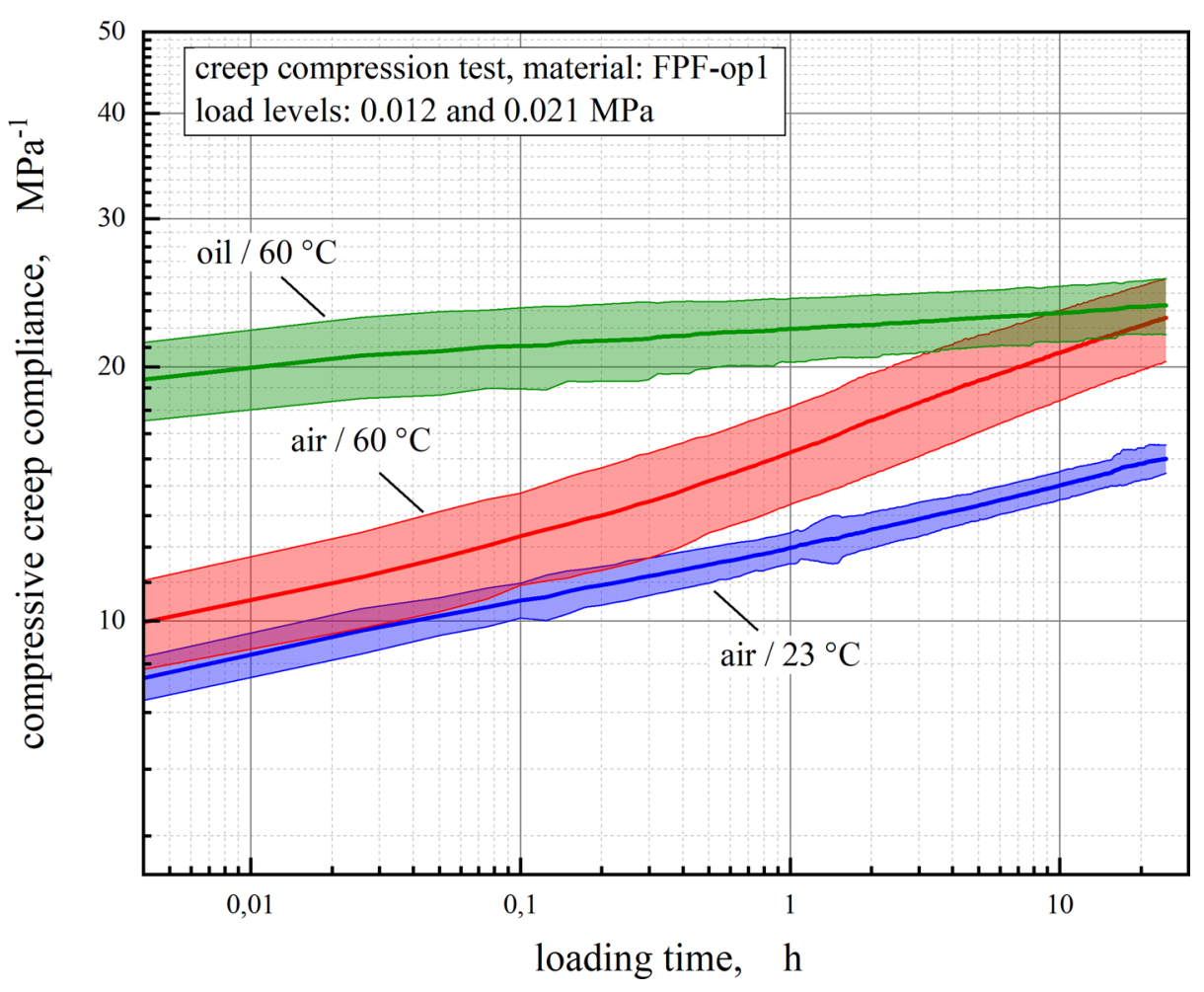

Fig. 6 Time dependency of creep compliance $D_{\mathrm{c}}(t)$ for the open cell PUR foam type FPF-op1 at test temperatures of $23^{\circ} \mathrm{C}$ and $60^{\circ} \mathrm{C}$ and for the oil immersed state at $60^{\circ} \mathrm{C}$

Finally, the corresponding creep compliance curves for the closed cell PUR foam type FPF-cl1 at stress levels of 0.099 and $0.103 \mathrm{MPa}$ are shown in Fig. 8. Mainly due to the denser, closed cell structure and the comparatively small amount of oil uptake, generally a low level of compressive compliance along with reduced creep tendency was observed for all test conditions investigated. In this case, temperature increase particularly in oil immersion leads to a slighter increase of the creep compliance due to temperature and media influence.

In an additional test series, the present PUR foam materials were investigated by dynamic-mechanical analysis (DMA) in compression mode to characterize the temperaturedependent storage modulus $E^{\prime}$ and the mechanical loss factor $\tan \delta$ within a temperature range from 30 to $100{ }^{\circ} \mathrm{C}$ (see Fig. 9). In good agreement with the creep properties of various PUR foam types, the temperature dependency of the corresponding dynamic-mechanical properties shows similar trends. Thus the quite temperature stable modulus and loss factor levels of closed cell foam type FPF-cl1 determined by DMA correlate with the lowest creep rate among the present foam types investigated. A slight increase of storage modulus with rising temperature is probably the result of thermal expansion of the foam specimens inducing larger stress amplitudes at constant dynamic elongation. Further on, entropy elastic effects of the elastomeric polymer could be a further reason for modulus increase in the regime above Tg (Schwarzl 1990). 


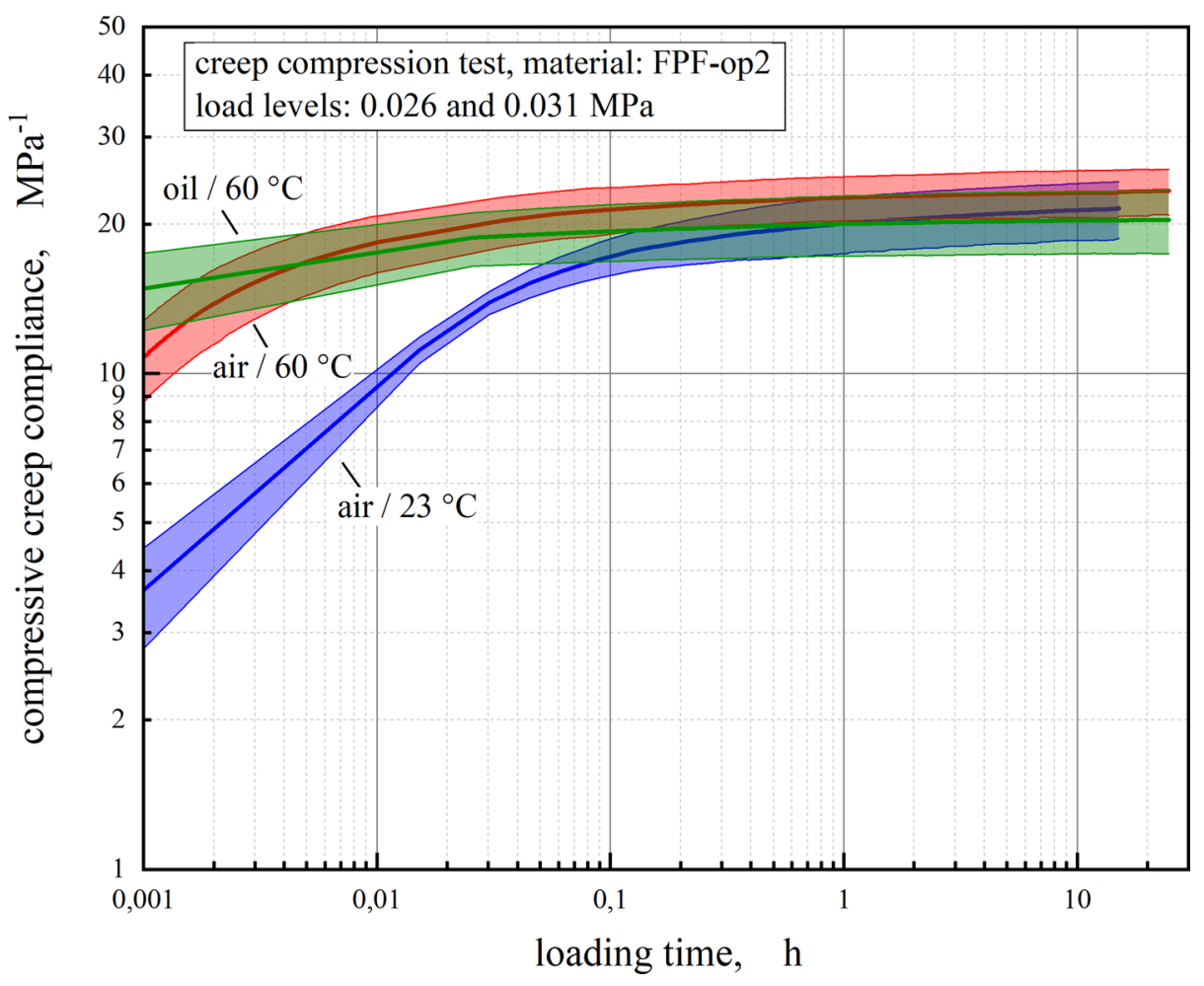

Fig. 7 Time dependency of creep compliance $D_{\mathrm{c}}(t)$ for the open cell PUR foam type FPF-op2 at test temperatures of $23^{\circ} \mathrm{C}$ and $60^{\circ} \mathrm{C}$ and for the oil immersed state at $60^{\circ} \mathrm{C}$

On the other hand, a temperature-dependent modulus decrease was determined for foam type FPF-op1, generally on a lower modulus regime for this open cell structured foam. The enhanced creep tendency of this material particularly at higher creep test temperature correlates with the distinctive temperature dependency of the storage modulus shown in DMA.

Finally, the second open cell foam type FPF-op2 showed the most significant decrease of the temperature-dependent compressive modulus in DMA along with the highest mechanical damping level among the foam materials investigated. This pronounced temperature dependency within the investigated range from 30 up to $100^{\circ} \mathrm{C}$ can be attributed to the glass transition temperature of $15^{\circ} \mathrm{C}$ for this foam type, which is close to the present test temperature range. As mentioned before, the neighboring glass transition is a dominant influencing factor for the creep behavior at room temperature and above and thus was also noticed in the pronounced increase of creep compliance for foam type FPF-op2 particularly in the initial time range at $23^{\circ} \mathrm{C}$.

\section{Summary}

A small load compression creep testing device suitable for the characterization of timedependent deformation of polymeric soft foam materials under static load was developed. 


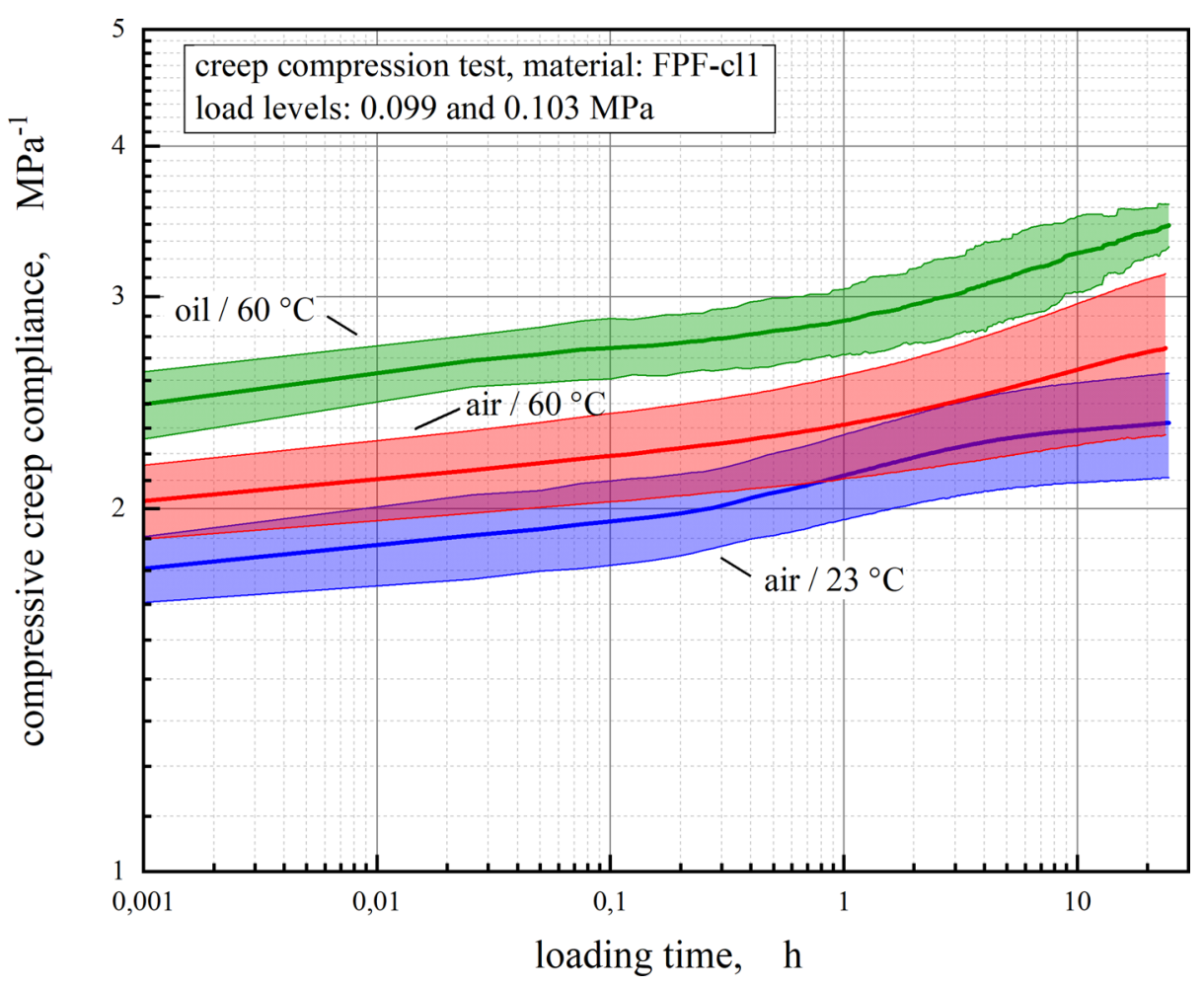

Fig. 8 Time dependency of creep compliance $D_{\mathrm{c}}(t)$ for the closed cell PUR foam type FPF-cl1 at test temperatures of $23^{\circ} \mathrm{C}$ and $60^{\circ} \mathrm{C}$ and for the oil immersed state at $60^{\circ} \mathrm{C}$

With the special focus on the performance of creep tests under direct liquid media influence, the test arrangement includes containers fillable with the specific liquid providing tests in media immersion. Moreover, the whole arrangement can be positioned in a temperature camber allowing the corresponding creep investigations also at elevated temperatures up to $80^{\circ} \mathrm{C}$.

Within the present study, this creep testing device was successfully implemented by creep investigations on various PUR soft foam materials with different densities and cell structures, both in dry state and immersed in mineral oil at 23 and $60{ }^{\circ} \mathrm{C}$. Depending on the individual structural state of the investigated foam types (cell size, open vs. closed cell structure), various materials showed distinct differences in their creep behavior according to the specific test parameters. In this regard, open cell structure and elevated temperature are enhancing factors for the materials creep, particularly for a temperature range close to glass transition. This result was also confirmed by additional thermomechanical analysis of the foam materials revealing temperature dependencies of the compressive storage modulus in good agreement with the corresponding creep behavior. Moreover, oil absorption of polymeric foam causes distinct materials softening, which results in larger initial deformation under creep load but reduced further creep deformation due to the larger compressed materials state. 


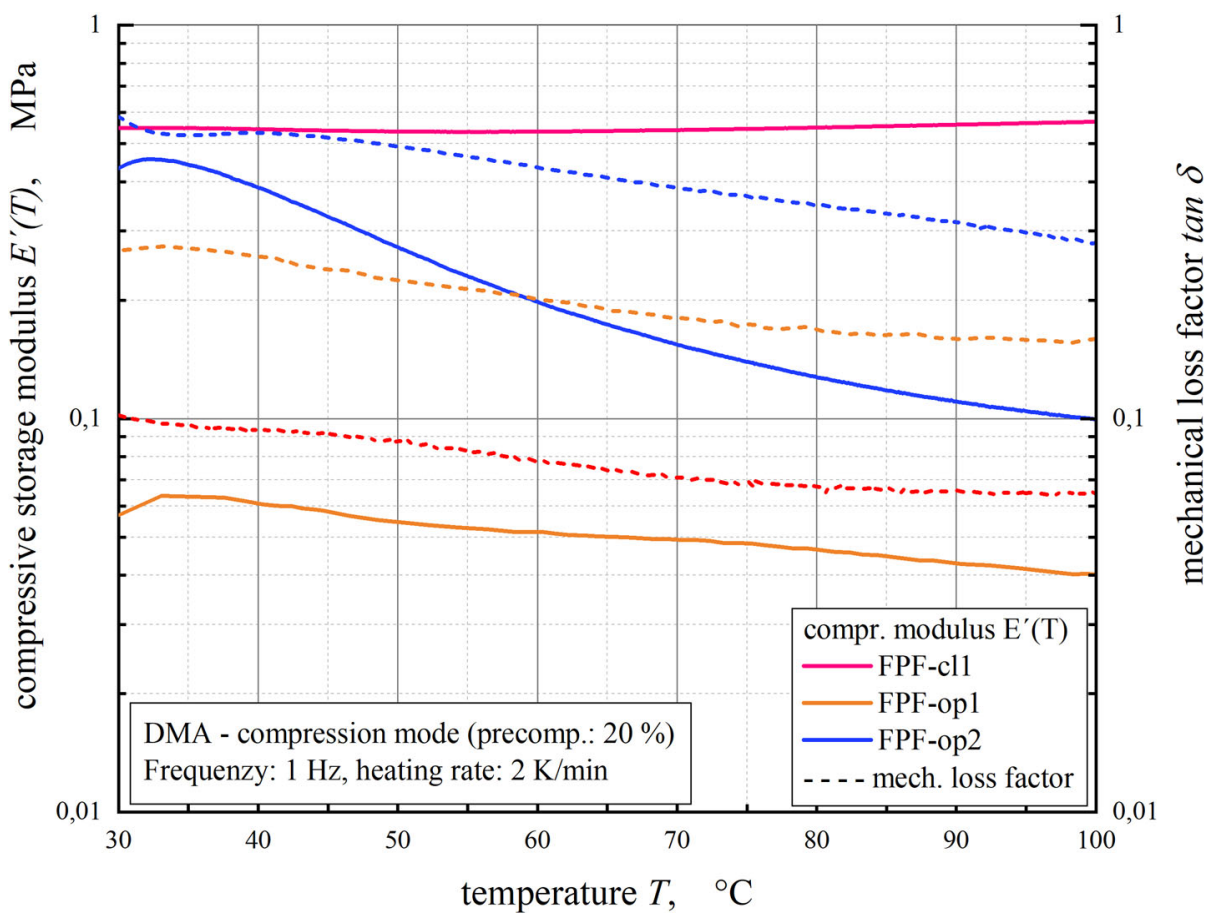

Fig. 9 Compressive storage modulus $E^{\prime}(T)$ and mechanical loss factor tan $\delta$ determined by DMA as functions of temperature for various PUR foam types

Funding Note Open access funding provided by Montanuniversität Leoben.

Publisher's Note Springer Nature remains neutral with regard to jurisdictional claims in published maps and institutional affiliations.

Open Access This article is licensed under a Creative Commons Attribution 4.0 International License, which permits use, sharing, adaptation, distribution and reproduction in any medium or format, as long as you give appropriate credit to the original author(s) and the source, provide a link to the Creative Commons licence, and indicate if changes were made. The images or other third party material in this article are included in the article's Creative Commons licence, unless indicated otherwise in a credit line to the material. If material is not included in the article's Creative Commons licence and your intended use is not permitted by statutory regulation or exceeds the permitted use, you will need to obtain permission directly from the copyright holder. To view a copy of this licence, visit http://creativecommons.org/licenses/by/4.0/.

\section{References}

Ashby, M.F.: The properties of foams and lattices. Philos. Trans. R. Soc., Math. Phys. Eng. Sci. 364, 15-30 (2006)

Biot, M.A.: Mechanics of Deformation and Acoustic Propagation in Porous Media. J. Appl. Phys. 33, 14821498 (1962)

Briody, C., Duignan, B., Jerrams, S., Ronan, S.: Polym. Test. 31, 1019-1025 (2012)

Cheng, A.H.: Poroelasticity Theory and Applications of Transport in Porous Media, vol. 27. Springer, Berlin (2016)

Corsaro, R.D., Sperling, L.H.: Sound and Vibration Damping with Polymers. American Chemical Society, Washington (1990) 
Defonseka, C.: In: Practical Guide to Flexible Polyurethane Foams. Smithers Rapra, Shrewsbury (2013)

Eaves, D.: Handbook of Polymer Foams. Rapra Technology Ltd., Shrewsbury (2004)

Ehrenstein, G.W., Theriault, R.P.: Polymeric Materials: Structure, Properties, Applications. Hanser, Munich (2001)

Ehrenstein, G.W., Riedel, G., Trawiel, P.: Thermal Analysis of Plastics: Theory and Practice. Hanser, Munich (2004)

Ferry, J.D.: Viscoelastic Properties of Polymers. Wiley, New York (1980)

Gibson, L.J., Ashby, M.F.: Cellular Solids: Structure and Properties. Cambridge University Press, Cambridge, New York (1999)

Hellerich, W., Harsch, G., Baur, E.: Werkstoff-Führer Kunststoffe Eigenschaften, Prüfungen, Kennwerte. Hanser, München (2010)

Kaushiva, B.D.: Structure-Property Relationships of Flexible Polyurethane Foam. PhD, Virginia Polytechnic Institute and State University (1999)

Mills, N.J.: Polymer Foams Handbook: Engineering and Biomechanics Applications and Design Guide. Butterworth-Heinemann, Oxford (2007)

Schwarzl, F.R.: Polymermechanik Struktur und mechanisches Verhalten von Polymeren. Springer, Berlin (1990)

Sonnenschein, M.F.: Polyurethanes: Science, Technology, Markets and Trends. Wiley, New Jersey (2014)

Szycher, M.: Szycher's Handbook of Polyurethanes. CRC Press, Boca Raton (2013) 